\title{
Spread and burning behavior of continuous spill fires
}

\author{
Zhao, Jinlong; Huang, Hong; Jomaas, Grunde; Zhong, Maohua; Li, Yuntao
}

Published in:

Fire Safety Journal

Link to article, DOI:

10.1016/j.firesaf.2017.03.046

Publication date:

2017

Document Version

Peer reviewed version

Link back to DTU Orbit

Citation (APA):

Zhao, J., Huang, H., Jomaas, G., Zhong, M., \& Li, Y. (2017). Spread and burning behavior of continuous spill fires. Fire Safety Journal, 91, 347-354. https://doi.org/10.1016/j.firesaf.2017.03.046

\section{General rights}

Copyright and moral rights for the publications made accessible in the public portal are retained by the authors and/or other copyright owners and it is a condition of accessing publications that users recognise and abide by the legal requirements associated with these rights.

- Users may download and print one copy of any publication from the public portal for the purpose of private study or research.

- You may not further distribute the material or use it for any profit-making activity or commercial gain

- You may freely distribute the URL identifying the publication in the public portal

If you believe that this document breaches copyright please contact us providing details, and we will remove access to the work immediately and investigate your claim. 


\title{
Spread and burning behavior of continuous spill fires
}

\author{
JINLONG ZHAO ${ }^{1,2}$, HONG HUANG ${ }^{1}$, GRUNDE JOMAAS ${ }^{2,3}$, MAOHUA ZHONG $^{1}$, and YUNTAO \\ $\mathrm{LI}^{4}$ \\ ${ }^{1}$ Institute of Public Safety Research, Department of Engineering Physics \\ Tsinghua University, Beijing, China \\ ${ }^{2}$ Department of Civil Engineering, \\ Technical University of Denmark, Kgs. Lyngby, Denmark \\ ${ }^{3}$ BRE Centre for Fire Safety Engineering, University of Edinburgh, Edinburgh, UK \\ ${ }^{4}$ School of Mechanical and Transportation Engineering \\ China University of Petroleum, Beijing, China
}

\begin{abstract}
Spill fire experiments with continuous discharge on a fireproof glass sheet were conducted to improve the understanding of spill fire spread and burning. Ethanol was used as the fuel and the discharge rate was varied from $2.8 \mathrm{~mL} / \mathrm{s}$ to $7.6 \mathrm{~mL} / \mathrm{s}$. Three ignition conditions were used in the experiments; no ignition, instantaneous ignition and delayed ignition. The spread rate, regression rate, penetrated thermal radiation and the temperature of the bottom glass were analyzed. The experiments clearly show the entire spread process for spill fires. Further, the regression rate of spill fires at the quasi-steady burning was lower than that of pool fires and the ratio of the spill fires' regression rate to the pool fires' regression rate was found to be approximately 0.89 . With respect to the radiative penetration and the heat conduction between the fuel layer and the glass, a regression rate expression for spill fires was developed based on some modifications on existing expressions for pool fires. In addition, a complete phenomenological model for spill fires was developed by combining the characteristics of spread and burning. The model was verified by the experimental data and found to predict the spread process for spill fires with reasonable accuracy.
\end{abstract}

KEYWORDS: continuous discharge; spill fire; regression rate; model

\section{NOMENCLATURE LISTING}

$\begin{array}{clll}\Delta H_{e} & \text { heat of gasification }(\mathrm{kJ} / \mathrm{g}) & w_{\infty} & \text { a peak regression rate }(\mathrm{m} / \mathrm{s}) \\ Q_{d i s} & \text { fuel discharge rate }\left(\mathrm{cm}^{3} / \mathrm{s}\right) & w_{s} & \text { steady regression rate }(\mathrm{m} / \mathrm{s}) \\ R & \text { spread radius }(\mathrm{cm}) & q_{f} & \text { heat feedback }\left(\mathrm{kW} / \mathrm{m}^{2}\right) \\ R_{\max } & \text { maximum spread radius }(\mathrm{cm}) & q_{c o v} & \text { convective heat feedback }\left(\mathrm{kW} / \mathrm{m}^{2}\right) \\ S_{s t} & \text { steady burning area }\left(\mathrm{cm}^{2}\right) & q_{p e} & \text { penetrated thermal radiation }\left(\mathrm{kW} / \mathrm{m}^{2}\right) \\ T & \text { fuel temperature } & q_{\text {out }} & \text { heat loss of fuel layer }\left(\mathrm{kW} / \mathrm{m}^{2}\right) \\ T_{a} & \text { ambient temperature }(\mathrm{K}) & h & \text { fuel thickness }(\mathrm{mm}) \\ T_{b} & \text { fuel boiling point }(\mathrm{K}) & h_{\text {min }} & \text { minimum fuel thickness }(\mathrm{mm}) \\ Y_{s} & \text { smoke yield } & g & \text { gravitational acceleration }\left(\mathrm{m} / \mathrm{s}^{2}\right) \\ c_{p} & \text { fuel specific heat }(\mathrm{kJ} /(\mathrm{gK})) & k & \text { spread coefficient } \\ c_{g} & \text { glass specific heat }(\mathrm{kJ} /(\mathrm{gK})) & \rho_{g} & \text { fireproof glass density }\left(\mathrm{kg} / \mathrm{m}^{3}\right) \\ w_{t} & \text { real-time regression rate }(\mathrm{m} / \mathrm{s}) & t & \text { Time }(\mathrm{s})\end{array}$

\section{INTRODUCTION}

Overflows and leakage from oil product containers during storage and transportation may cause large damage and trigger further accidents especially in the case of ignition [1-2]. It is important for risk management to investigate the fuel spread, burning, and thermal radiation of spill fires. The spill fire has two main aspects: the spread behavior and the burning behavior. At present, some models have already been established to predict the spread and burning behaviors. For the fuel spread, the spread of LNG and oil on water or on land has received considerable attention the past few decades [3-4]. In these studies, different versions of pool spread model based on various simplifications have been provided and these have been summarized by Webber et al. [5]. For the fuel burning, many experiments with burning diameters ranging from around 0.01 meters to around 80 meters have been carried out to study the steady-state burning rate [6]. Based on these experiments, empirical models have been established, and these are 
gathered and discussed by, for example, Babrauskas [7] and Ditch et al. [8]. As a result, the existing models for spread and burning can lay a foundation for spill fire research.

To date, the combination of the spread and the burning has been taken into account by some researchers and a 'complete' model for spill fires has been proposed [4]. In these models, it is obvious that the fuel consumption due to burning is crucial in the spread process, and the quasi-steady burning is directly determined by the burning rate of the spill fire for a certain discharge rate [9]. However, the burning rate of pool fires is directly considered that of spill fires in some cases, even though this has been proved wrong by Gottuk et.al [10] and Mealy et al. [11]. They found that the burning rate of spill fires is lower than that of pool fires and in some situations the ratio of the spill fires' burning rate to that of pool fires is less than 0.5. Gottuk and White provided a depth coefficient that was introduced to modify the pool fires' burning rate model in the newest edition of the SFPE Handbook for Fire Protection Engineering [12]. Still, they did not further discuss the reason for the decrease of the burning rate. In their descriptions, the available experimental data for continuous spill fires are not sufficient to explain the burning rate decrease because the temperature of the substrate and the transmitted thermal radiation were not measured [12]. However, spill fire accidents often evolve into the continuous discharge situations, as exemplified by the "7.16" oil pipeline fire accidents of Dalian [13]. As a result, continuous discharge spill fires should be paid more attention to and the burning rate's decrease should be further discussed.

Herein, some continuous spill fire experiments were conducted to display the entire spread process and burning behaviors. In order to find the main reasons leading to the regression rate decrease, the penetrated thermal radiation was measured by using the transparent fireproof glass. Then the heat loss of fuel layer was estimated and an empirical regression rate model is provided by some modifying an existing pool fire model. In the end, a basic spill fire model is developed that describes the entire spread process.

\section{METHODOLOGY}

\section{Experimental Set-up}

Figure 1 shows the schematic diagram of the experimental apparatus. The fireproof glass was selected as the spread surface because it could provide a level surface for fuel spread. In addition, the radiative penetration could also be measured due to the transmittance property of the glass. The fireproof glass was 1 $\mathrm{m}$ long, $1 \mathrm{~m}$ wide and $10 \mathrm{~mm}$ thick. A $10 \mathrm{~mm}$ diameter hole was punched at the center of the glass to allow for connecting a tube. The ethanol was released continuously with different discharge flow rates from a fuel container to the surface of the fireproof glass by a peristaltic pump. A balance (Sartorius) with a range from $0 \mathrm{~kg}$ to $35 \mathrm{~kg}$ with an accuracy of $0.1 \mathrm{~g}$ was used to measure the residual ethanol mass. Then the discharge rate can be calculated by analyzing the average change in mass over a period of time. Three water-cooled heat flux gages were installed under the glass and used to measure the transmitted thermal radiation. They were separately located $5 \mathrm{~cm}, 15 \mathrm{~cm}$ and $25 \mathrm{~cm}$ away from the center of the glass. In addition, three patch thermocouples were positioned symmetrically with respect to the heat flux gages at the center of the glass. Finally, ten K-type thermocouples were arranged at the vertical axis of the glass surface and the separation distance between each was $10 \mathrm{~cm}$. During the experiments, the fuel spread rate and the flame height were recorded by two digital video recorders (Sony HDRXR260E). By analyzing the red, blue, and green (RGB) values of every pixel, the flame area $(R>180, G>90, B>70)$ could be captured and then the flame height and burning area could be determined.

It was an important work to keep the glass surface level because a small inclination would have a significant effect on the spread behavior. Before each experiment, a levelling instrument with an accuracy of $0.01^{0}$ was used to check whether the surface is level. And then we used the pump to input water first to confirm whether the water can spread uniform on the glass surface. 


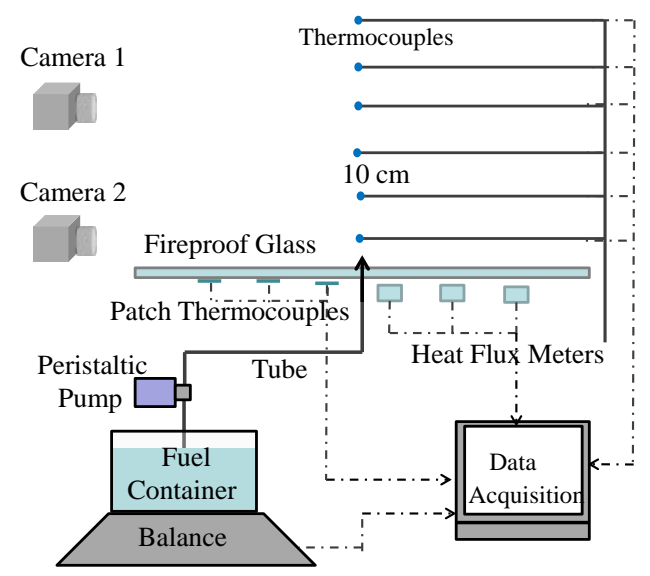

Fig. 1. Schematic diagram of the experimental apparatus

The spill fire experiments were performed in a large test hall $(30 \mathrm{~m} \times 14 \mathrm{~m} \times 9 \mathrm{~m})$. During the test, the doors and windows were closed, but not sealed. Each experiment was repeated three times. The experiments were conducted at around $28 \pm 4{ }^{\circ} \mathrm{C}$. The ethanol spill was; (1) ignited immediately, (2) ignited after a certain delay after the release, and (3) not ignited, as specified in Table 1.

Table 1. Specification of the test conditions

\begin{tabular}{ccccc}
\hline $\begin{array}{c}\text { Test } \\
\text { Number }\end{array}$ & $\begin{array}{c}\text { Discharge Rate } \\
(\mathrm{mL} / \mathrm{s})\end{array}$ & $\begin{array}{c}\text { Discharge } \\
\text { Time }(\mathrm{s})\end{array}$ & $\begin{array}{c}\text { Total Discharged } \\
\text { Volume }(\mathrm{mL})\end{array}$ & $\begin{array}{c}\text { Ignition } \\
\text { Delay }(\mathrm{s})\end{array}$ \\
\hline 1 & 2.76 & 310 & 860 & 0 \\
2 & 2.76 & 304 & 840 & 20 \\
3 & 2.76 & 90 & 240 & $\infty$ \\
4 & 4.20 & 260 & 1095 & 0 \\
5 & 4.20 & 302 & 1280 & 20 \\
6 & 4.20 & 80 & 335 & $\infty$ \\
7 & 5.76 & 278 & 1650 & 0 \\
8 & 5.76 & 304 & 1710 & 20 \\
9 & 5.76 & 42 & 240 & $\infty$ \\
10 & 7.55 & 269 & 2030 & 0 \\
11 & 7.55 & 37 & 280 & $\infty$ \\
\hline
\end{tabular}

\section{Model Descriptions}

The spread process is controlled by the force of gravity, viscosity and friction [14]. There are many different models in the spread field because of different understanding and different simplifications. The integral spread model on land is developed in PHAST considering the pool spread, vaporization and heat conduction [15].

$$
\frac{d R}{d t}=k \sqrt{g\left(h-h_{\min }\right)}
$$

where $R$ is the spread radius(m), $t$ is the spread time(s), $g$ is the acceleration due to gravity $\left(\mathrm{m} / \mathrm{s}^{2}\right), h$ is average fuel thickness $(\mathrm{m}), k$ is an empirical constant whose value can be determined from experimental data. $h_{\min }$ is the minimum spread fuel thickness which is provided for some fuels in PHAST [15] and the value can be calculated using the experimental data.

The fuel front spread rate becomes zero when the thickness of the pool reaches its minimum height ( $h=$ $\left.h_{\min }\right)$. Many authors, including Brambilla and Manca [16] and Webber [17], have declared that it is a mistake for spread on land to neglect the friction part. However, the effect of friction would decline 
significantly for longer duration spills based on the Manning formula with the flow being under the laminar flow condition. Therefore, it is reasonable to select Eq. 1 as a basic model to assess the ethanol continuous spread process. Compared with the spread, there are many special phenomena for spill fires, such as the shrinking phenomenon which cannot be predicted by the spread model. In addition, the quasi-steady burning area is determined by the burning rate for long time burning. Combined with the above descriptions for the entire spread and burning process, the whole spread process can be simplified as:

$$
R_{t}=\left\{\begin{array}{lr}
\mathrm{R}_{t-1}+k \sqrt{g\left(h-h_{\text {min }}\right)} \Delta t & \left(t<t_{1}\right) \\
R_{\text {max }} & \left(t_{1} \leq t<t_{2}\right) \\
\sqrt{Q_{\text {dis }} /\left(\pi w_{s}\right)} & \left(t \geq t_{2}\right)
\end{array}\right.
$$

where $t_{1}$ is the time when the spread area reaches the maximum burning area(s), $w_{s}$ is the quasi-steady regression rate $(\mathrm{m} / \mathrm{s})$ and $Q_{\text {dis }}$ is the discharge rate $\left(\mathrm{m}^{3} / \mathrm{s}\right), t_{2}$ is the time when the spread area begins to shrink, $\triangle t$ is the time interval in the calculation. The burning consumption equals to the discharge rate for a longer spread burning $\left(t>t_{2}\right)$ and then the spread burning area can be determined based on the volume conservation. For the spread process, the fuel thickness equals to the minimum fuel thickness when the spread area reaches the maximum burning area. The fuel consumption rate is larger than the discharge rate at that time because of the pre-accumulation. In fact, some area more than the quasi-steady part $\left(>Q_{d i s} / w_{s}\right)$ cannot get the sufficient fresh fuel due to the fuel consumption. During this period, the regression rate is simplified as a constant. And then the sustained burning time of the maximum burning area can be estimated according to volume conservation.

$t_{2}-t_{1}=h_{\min } / w_{s \max }$

where $w_{s \max }$ is the regression rate corresponding to the maximum burning area.

The fuel thickness is determined by the spread rate and the burning consumption for spill fires, which can be estimated based on mass conservation.

$h(t)=\left(Q_{d i s} t-\int_{0}^{t} w_{t} \pi R^{2}(t) d t\right) / \pi R^{2}(t)$

The burning rate of spill fires is given by Gottuk and White in the chapter on Liquid Fuel Fires in the SFPE Handbook [12].

$\dot{w}_{t}=C_{\delta} \dot{w}_{\infty}\left(1-e^{-k \beta D}\right)$

where $\dot{w}_{t}$ is real-time regression rate of spill fires, $C_{\delta}$ is a function of pool depth and needs to confirmed by experiments, which is shown in Eq.(6), $w_{\infty}$ is the peak regression rate for the given fuel (m/s), $k \beta$ is an empirical constant to the fuel, $D$ is the pool dimeter.

$C_{\delta}=1-q_{\text {out }} / q_{\text {fback }}$

where $q_{\text {out }}$ is the heat loss of the fuel layer related to the thickness of fuel layer $\left(\mathrm{kW} / \mathrm{m}^{2}\right)$ and $q_{\text {fback }}$ is the heat feedback from the flame $\left(\mathrm{kW} / \mathrm{m}^{2}\right)$.

Based on the model, the fuel spread process can be predicted for spill fires. However some important factors are not included in our models. For example, we cannot evaluate the boiling process for spill fires because the effect of the produced bubbles at boiling on the fuel spread is still unknown.

\section{RESULTS AND DISCUSSION}

\section{Spread process without ignition}

A video camera lens kept a certain angle to the experimental platform and it was ensured that the entire surface was in the pictures. In the analysis, one picture per second from the recorded video was used. By analyzing the pixel properties of the fuel spread front, the spread diameter can be calculated according to a certain scale. Fig. 2 shows the detail spread process with no ignition. 


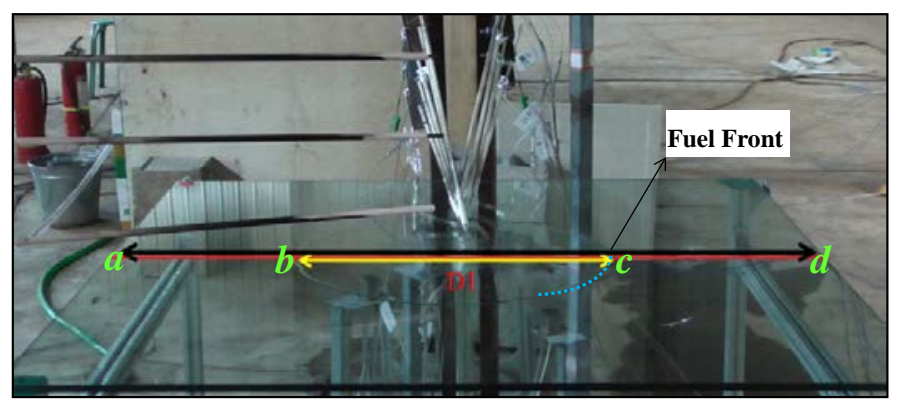

Fig.2. The detailed spread process without ignition. The discharge rate is $4.2 \mathrm{~mL} / \mathrm{s}$.

In Fig. 2, the spread diameter $D_{1}$ can be expressed as:

$$
D_{1}=\frac{c-b}{d-a}
$$

where $a$ and $d$ are the pixel coordinates, representing the edge of the fireproof glass (the practical length between $a$ and $d$ is $1 \mathrm{~m}$ ), $c$ and $d$ represent the fuel front position.

Using this method, the spread diameter can be calculated and Fig. 3 presents the variation of the spread radius and spread rate with the discharge time with no ignition.
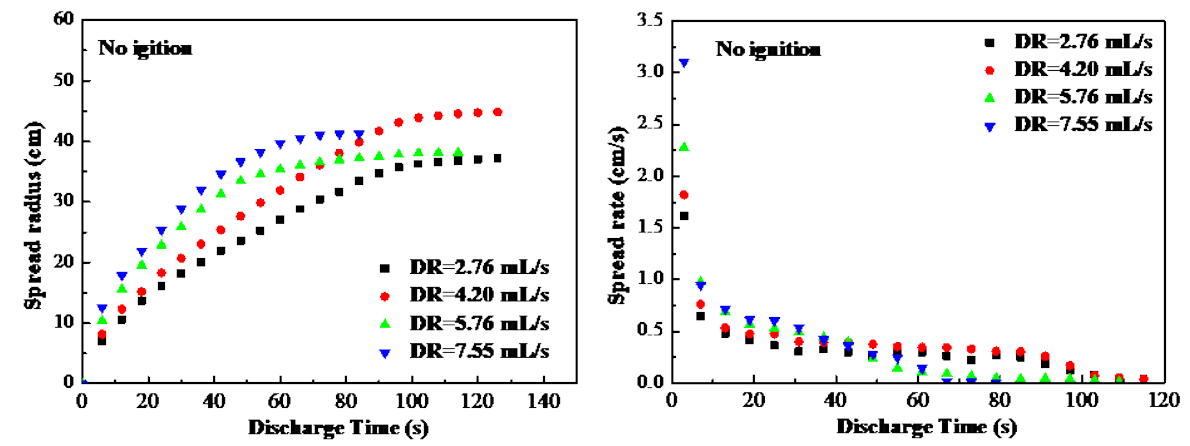

Fig.3. The spread radius, spread rate vs the discharge time with no ignition. DR is the discharge rate.

In Fig.3, we can observe that the higher the discharge rate, the faster the spread rate. In Test 3 (DR=2.76 $\mathrm{mL} / \mathrm{s}$ ) and Test $9(\mathrm{DR}=5.76 \mathrm{~mL} / \mathrm{s})$, the total discharge amount is close to $240 \mathrm{ml}$ and the maximum spread area has approximately the same value, which illustrates that the maximum burning area is not related to the discharge rate and the spread rate. From the observation of the entire process, we can find that the spread rate is high at the initial stage and then experiences a fast decline. The decline rate gradually tends to be relatively small for a long time spread. During the process, the decrease of the average fuel thickness directly leads to this behavior which can be well explained by Eqs.1 and 4. From Fig. 3, the maximum radius $\left(R_{\max }\right)$ can be obtained and the minimum fuel thickness can be calculated as:

$$
h_{\text {min }}=\frac{Q_{\text {dis }} t}{\pi R_{\max }^{2}}
$$

where $t$ is the discharge time, $R_{\max }$ is the maximum spread radius.

According to Eq.7, for the four tests shown in Fig. 3, the minimum fuel thickness is $0.51 \mathrm{~mm}, 0.47 \mathrm{~mm}$, $0.48 \mathrm{~mm}$ and $0.46 \mathrm{~mm}$. In this paper, we take the average value $0.48 \mathrm{~mm}$ as the fuel spread minimum value. In addition, the spread coefficient $k$ can be calculated and its value is approximately 0.146 . 


\section{Spread process with ignition}

The spread rate of spill fires refers to the flame spread rate in the radial direction from the discharge source because the flame can cover the entire spread area in a short time. Fig. 4 shows the entire spread process when the discharge rate is $5.76 \mathrm{~mL} / \mathrm{s}$ (Test 7).

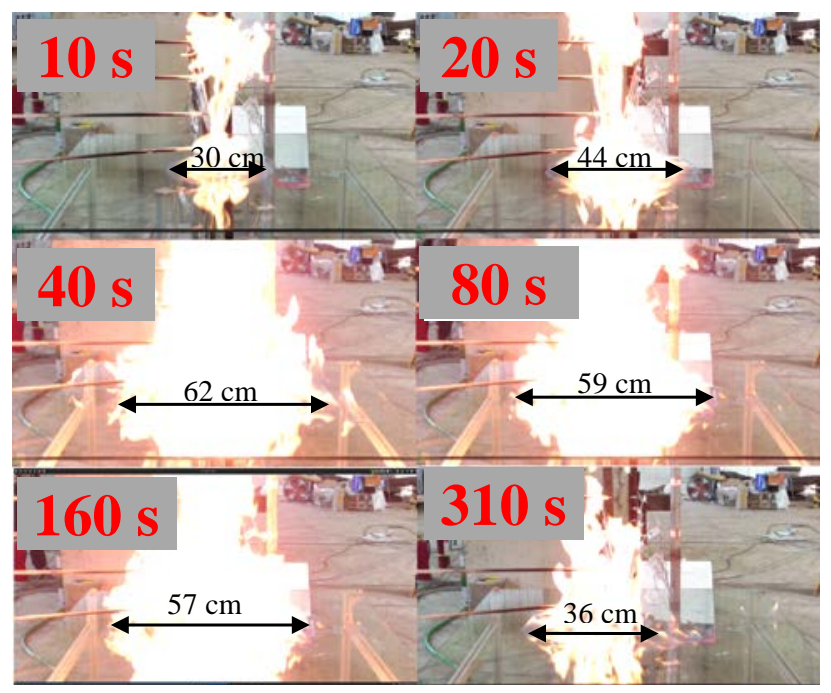

Fig.4. The general spread process in Test 7. The discharge rate is $5.76 \mathrm{~mL} / \mathrm{s}$.

The ethanol is ignited easily although the fuel layer is relatively thin. At the beginning of burning, the flame height and the burning radius increase rapidly with increasing discharge time. With the development of spread, the burning radius and the flame height all tend to stabilize. Then, this steady burning process nearly takes up the most of the entire burning time. In the end, the fire extinguished quickly as the fuel supply was interrupted by cutting off the pump. By analyzing the variation of burning (flame) diameter, the detail spread process is shown in Fig. 5.

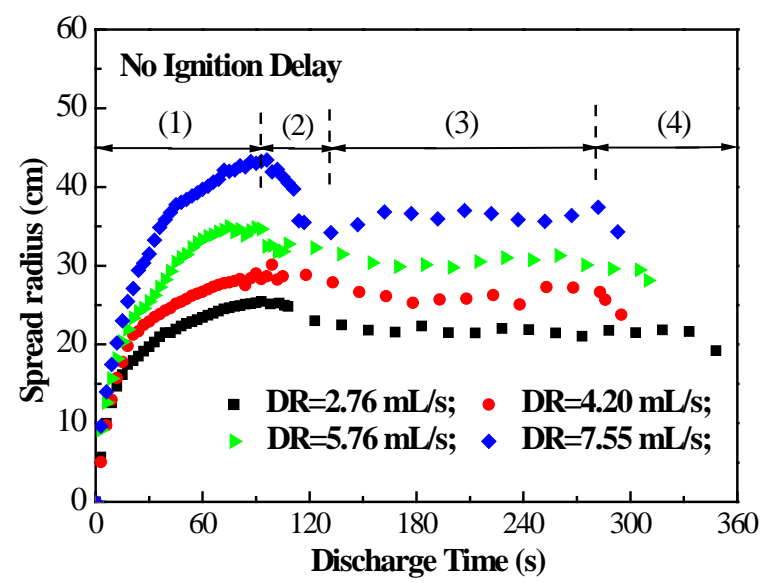

Fig. 5. The variation of the spread radius with the discharge time.

According to Fig. 5, we can conclude that the spread process can be divided into four burning phase: (1) spread burning phase, (2) shrink burning phase, (3) quasi-steady burning phase, and (4) extinguishment phase. During the spread burning phase, the burning radius is continuously increasing with the discharge time, but the spread rate has the opposite trend. At the end of the spread burning phase, the burning radius reaches its maximum value, which directly determines the open area contacted by the fire. During the shrink burning phase, the burning radius begins to decrease because the fuel consumption rate is greater than the discharge rate. The fresh fuel cannot reach to the burning front during this burning phase. 
Compared with the other burning phase, the quasi-steady burning lasts longer and the burning radius keeps relatively stable. As a result, firefighters are likely to encounter this burning phase in most spill fire cases. It is possible to calculate the discharge rate if the burning rate is known in some actual spill fire's accidents. So it is important to study this burning phase in detail. During the extinguishment phase, the spill fire extinguishes rapidly due to fuel depletion.

In our experiments, the effect of the delayed ignition is considered and Fig.6 shows the variation of the spread radius with the discharge time under the 20 s delay ignition conditions.

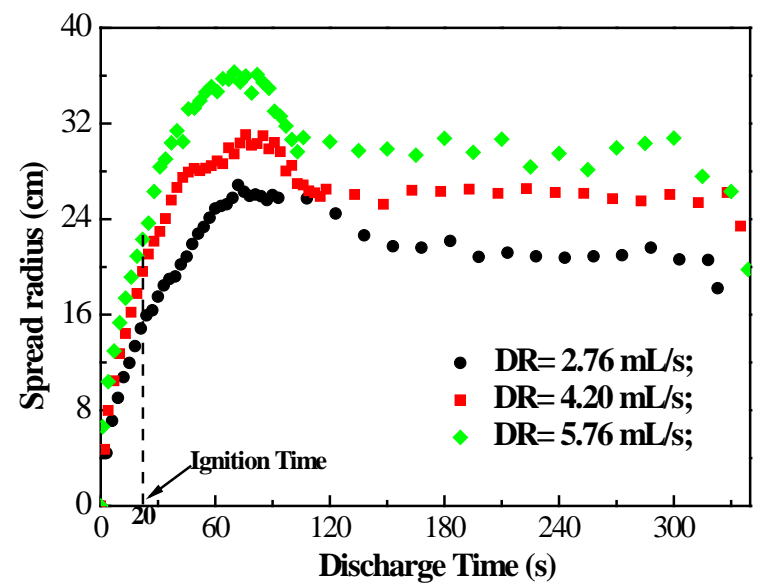

Fig. 6. The variation of the spread radius with the discharge time for 20s delayed ignition

Figure 6 shows that the spread process can also be divided into four burning phases under the delayed ignition conditions. Compared with Fig.5, it can be concluded that the quasi-steady burning radius is close to the same value for the same discharge conditions, and is therefore independent of the delayed ignition. So it can also illustrate that the quasi-steady burning area is directly determined by the burning consumption for a fixed discharge rate. Although the delayed ignition has no effect on the quasi-steady burning radius, the maximum burning radius will expand in the case of delayed ignition, which enlarges the open fire contacted area.

\section{Regression rate of spill fires}

In the quasi-steady burning, the spread area keeps relatively stable and the fuel is burned at the rate at which it is being discharged. According the mass conservation, the regression rate of this phase can be calculated.

$$
\dot{w}_{s}=\frac{Q_{\text {dis }}}{S_{s t}}
$$

where $S_{s t}$ is the quasi-steady burning area $\left(\mathrm{m}^{2}\right)$, which can be estimated by Fig.5. Fig. 7 displays the burning rate at the quasi-steady burning phase. 


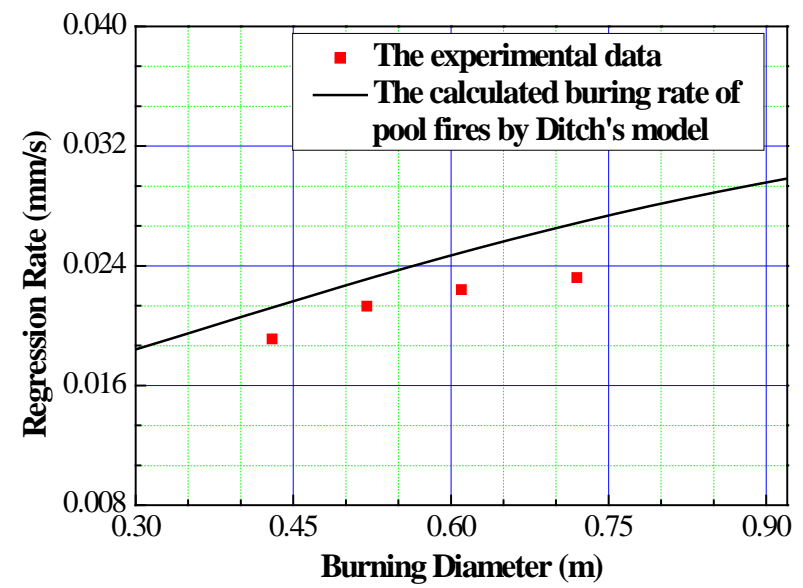

Fig. 7. The regression rate comparison between spill fires and pool fires

The regression rate of spill fires is smaller than that of pool fires from Fig.7 and the ratio is close to 0.89. Compared with other experiments on spill fires, this value is relative larger than those on concrete and on water [9-10]. In order to analyze the reason and develop a regression rate model of spill fires, the heat transfer process for spill fires is analyzed.

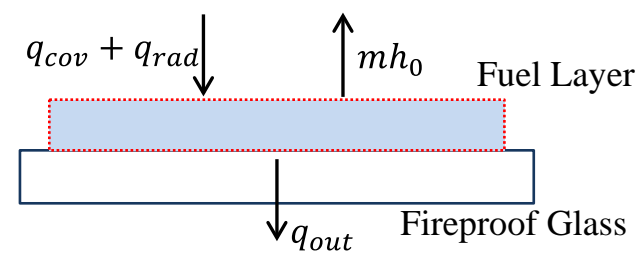

Fig. 8. The heat transfer process for spill fires

The heat transferred to the fuel inside is considered to be entirely absorbed and the heat loss to the substrate, $q_{\text {out }}$, is ignored for pool fires. Based on the energy conservation, Ditch et al. proposed a regression rate model of pool fires [8].

$$
\begin{aligned}
& q_{f}=12.5+68.3 Y_{s}^{0.25}\left(1-\exp \left(-\left(\frac{8}{3}\left(\Delta H_{e}+c_{p}\left(T_{b}-T_{a}\right)\right) R\right)^{1.5}\right)\right) \\
& \dot{w}_{\text {pool }}=q_{f} / \rho\left(\Delta H_{e}+c_{p}\left(T_{b}-T_{a}\right)\right)
\end{aligned}
$$

where $q_{f}$ is the heat transfer per unit surface area of the pool including the convective $\left(12.5 \mathrm{~kW} / \mathrm{m}^{2}\right)$ and radiative component, $\triangle H_{e}$ is the heat of gasification, $Y s$ is the smoke yield (0.008 for methanol[18]), $D$ is the pool diameter, $c_{p}$ is the specific heat, $T_{b}$ is the boiling point and $T_{a}$ is the ambient temperature.

The heat loss from the fuel layer $q_{\text {out }}$ should be considered for spill fires because the thickness of fuel layer is in the millimeter range [12]. Therefore, the regression rate model of spill fires can be expressed as:

$$
\dot{w}_{t}=\left(q_{f}-q_{\text {out }}\right) /\left(\Delta H_{e}+c_{p}\left(T_{b}-T_{a}\right)\right)
$$

In our experiments, the heat loss can be divided into two parts: one is the heat conduction from the fuel layer to the fireproof glass $\left(q_{c o d}\right)$ and the other part is penetrated thermal radiation that passes through the fuel layer and glass to the air $\left(q_{p e}\right)$.

$$
q_{\text {out }}=c_{g} \rho_{g} A \int_{0}^{h_{g}} \frac{d T}{d t} d h+q_{p e}
$$


where $c_{g}$ is the specific heat of the fireproof glass, $\rho_{g}$ is the glass's density, $h_{g}$ is the glass's thickness, $T$ is the measured temperature by the coupled thermocouples installed under the glass and $A$ is the unit area $\left(1 \mathrm{~m}^{2}\right)$. In our calculation, the temperature distribution in the vertical direction of the glass can be simplified as a linear distribution. And the convection part between the bottom glass and the air is neglected.

The properties of the ethanol and the fireproof glass related to the heat loss calculation are given in Table 2 .

Table 2. Properties of the ethanol and the fireproof glass

\begin{tabular}{ccccc}
\hline Material & $\begin{array}{c}\text { Specific heat capacity } \\
\mathrm{kJ} /(\mathrm{kg} \mathrm{K})\end{array}$ & $\begin{array}{c}\text { Density } \\
\left(\mathrm{kg} / \mathrm{m}^{3}\right)\end{array}$ & $\begin{array}{c}\text { Heat of vaporization } \\
(\mathrm{kJ} / \mathrm{kg})\end{array}$ & $\begin{array}{c}\text { Boiling point } \\
\left({ }^{\circ} \mathrm{C}\right)\end{array}$ \\
\hline Ethanol & 2.42 & 790 & 847 & 78 \\
Fireproof glass & 0.84 & 2500 & 1 & 1 \\
\hline
\end{tabular}

In order to address the heat loss of spread layer, the penetrated thermal radiation is measured by radiation gauges. Fig.9 shows the variation of the penetrated thermal radiation with the burning time.

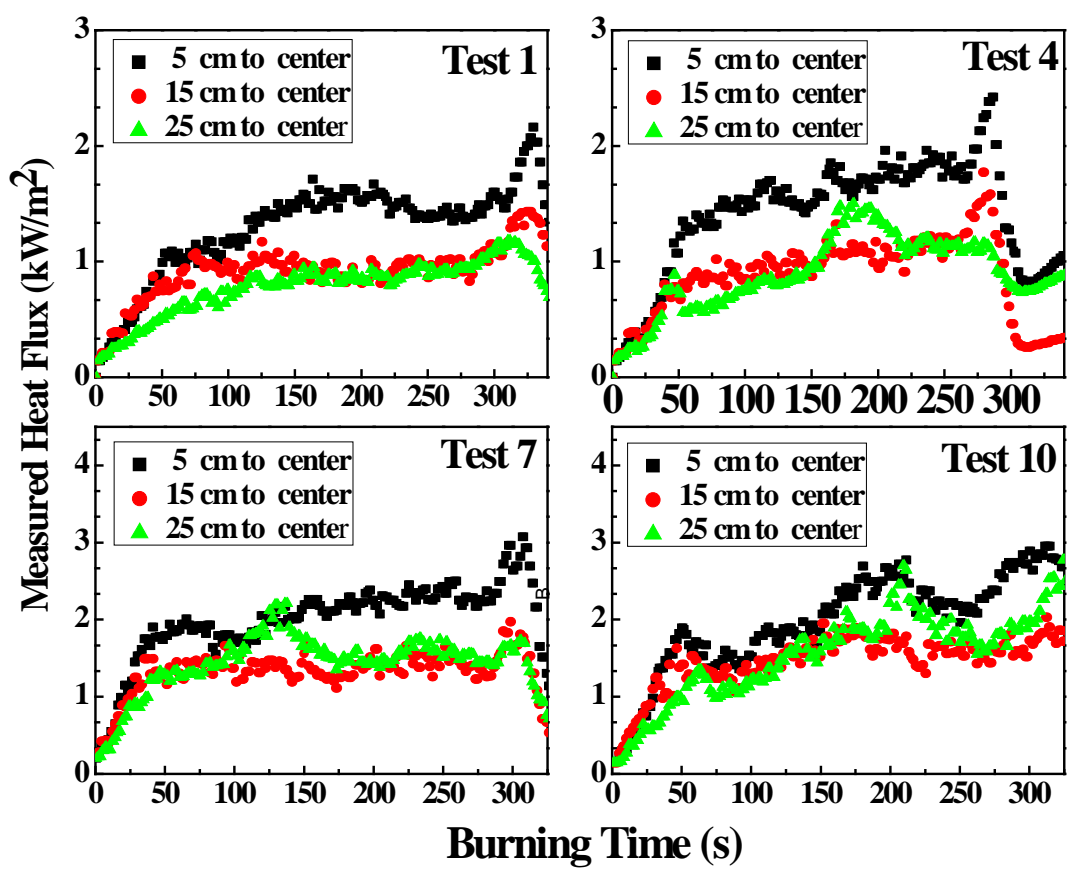

Fig. 9. The variation of the penetrated thermal radiation with the burning times

Figure 9 shows that the penetrated thermal radiation increases quickly with the burning time during the spread burning phase. During quasi-steady burning, the thermal radiation keeps relatively stable although there are some small fluctuations, which correlates with the change in the burning area. The stable penetrated thermal radiation also indicates that the heat feedback at the quasi-steady burning phase is stable. On the other hand, it can conclude that the heat feedback increases approximately from $17 \mathrm{~kW} / \mathrm{m}^{2}$ to $25 \mathrm{~kW} / \mathrm{m}^{2}$ when the burning diameter goes from $0.3 \mathrm{~m}$ to $0.7 \mathrm{~m}$, based on Eq. 10. Meanwhile, the penetrated thermal radiation increases approximately from $0.95 \mathrm{~kW} / \mathrm{m}^{2}$ to $1.65 \mathrm{~kW} / \mathrm{m}^{2}$ in Fig.9. In Fig.7, the ratio of the quasi-steady regression rate of spill fires to that of pool fires is about 0.89 , which means approximately $11 \%$ of heat feedback is lost. Based on the measured radiative penetration and calculated heat loss, we can find that the penetrated thermal radiation accounts for about $50 \%$ of the heat loss $\left(q_{p e} / q_{\text {loss }}\right)$. As a result, the penetrated thermal radiation is the main factor for the decrease of the regression rate for spill fires on a transparent substrate. 
The temperature of the glass bottom surface is measured by the patch thermocouples and the layout has been shown in Fig.1. The temperature variation with the burning time is shown in Fig. 10.

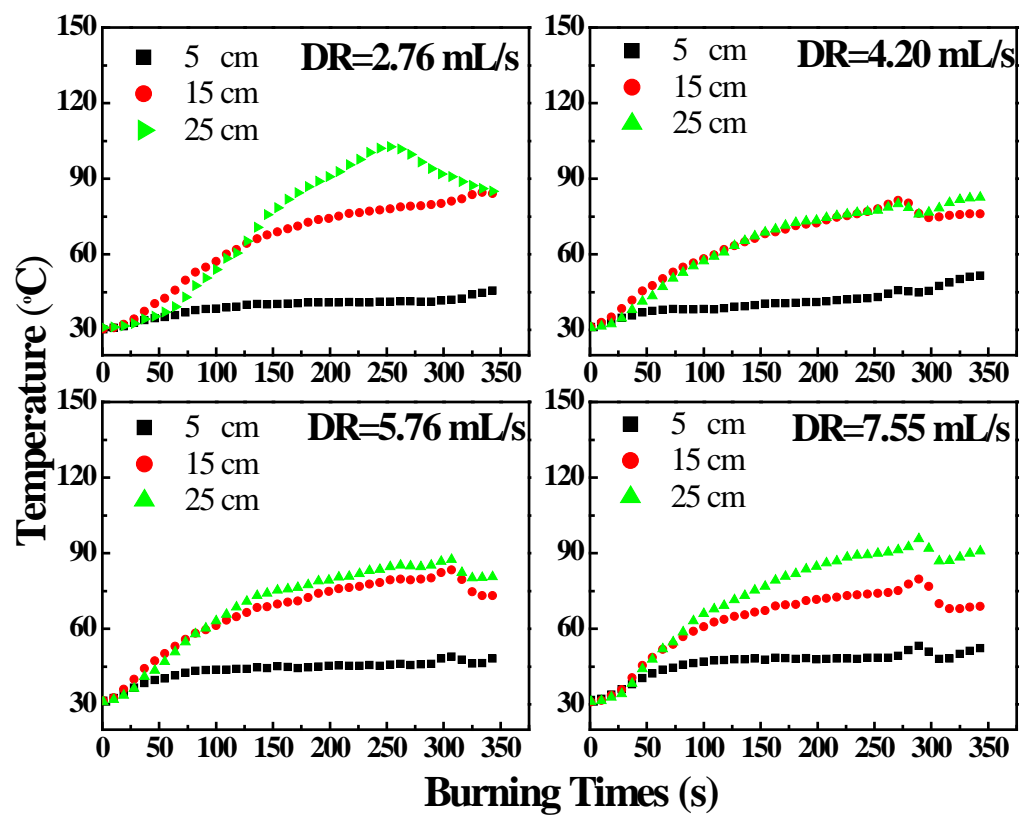

Fig. 10. The temperature variation with the burning time for the bottom surface with no delay ignition.

The temperature of the glass underside increases rapidly during the spread burning phase and gradually tends to stabilize from Fig. 10. The temperature near the discharge position is lower than the other two positions because the fresh fuel is relatively cold. After a period of burning, most the area of the bottom surface has achieved the boiling point of ethanol $\left(78{ }^{\circ} \mathrm{C}\right)$ and the temperature variation is nearly close to zero. In Test 1 (DR=2.76 mL/s), the burning radius is approximately $25 \mathrm{~cm}$, so the glass near the spread front directly contacts with the flame and has a higher temperature (above the boiling point). In Fig. 10, the $\mathrm{dT} / \mathrm{dt}$ can be confirmed and then the heat conduction can be estimated based on Eq.13. The calculation shows the heat conduction can reach approximately $2.8 \mathrm{~kW} / \mathrm{m}^{2}$ at the initial spread burning phase and then gradually tend to small. This result clearly shows that heat conduction has an obvious effect on the regression rate decrease, compared with total heat loss of fuel layer. Then by combining the penetrated thermal radiation with heat conduction, we can calculate the ratio of heat loss to feedback heat and find that it is approximately 0.12 , which is consistent with the experimental data.

\section{Validation of the spread model}

Equations (1-7) present an analytical model for a continuous spill fire. In the models, the burning consumption is neglected when the burning diameter is less than $0.2 \mathrm{~m}$ because the regression rate model is not clear in this range. The parameters used in the simulation are provided in Table 1 and Table 3. Fig. 11 shows a comparison between the experimental data and calculated values by the models.

Table 3. Spread and burning properties of ethanol

\begin{tabular}{cc}
\hline Properties & Value \\
\hline Minimum thickness $(\mathrm{mm})$ & 0.48 \\
Spread coefficient $k$ & 0.1458 \\
Regression Rate $(\mathrm{mm} / \mathrm{s})$ & $C_{\delta} w_{\text {pool }}$
\end{tabular}




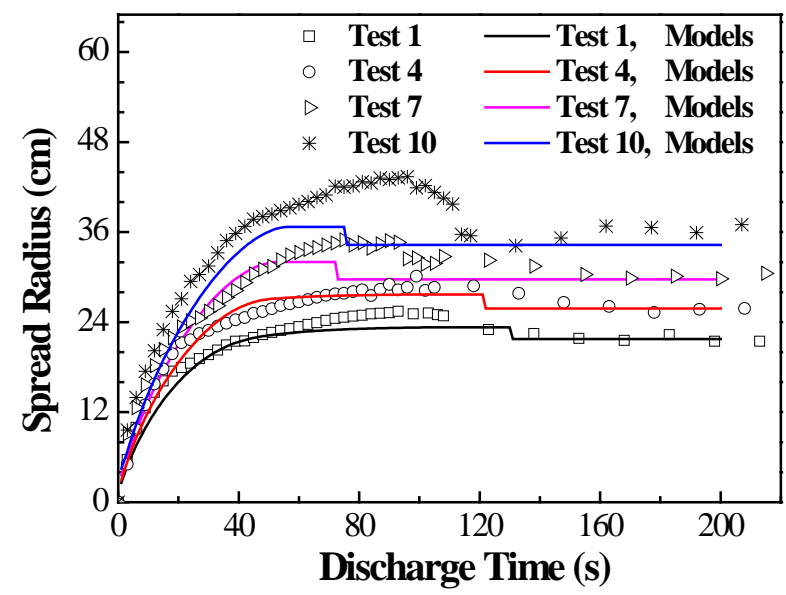

Fig. 11. The comparison between the experimental data and calculated values by the models

The result shows a reasonable agreement between the experimental data and the model predictions from Figure 11. However, the predicted maximum spread radius is smaller than the experimental value, whose maximum relative error is less than $16 \%$ and average relative error is less than $9.8 \%$. In our model, the variations of physical properties like viscosity and surface tension with temperature and the effect of the combustion vapors are not considered. These effects will become obvious when the spread rate is low, which well explains the deviation between the maximum predicted value and experimental value. In addition, we make a simplification during the calculation of the heat conduction. This is also an important reason leading to the deviation of the maximum burning areas.

\section{CONCLUSION}

Spill fire experiments on a fireproof glass surface were conducted to further understand the spread and burning behavior of spill fires, including a detailed study of the radiative heat transfer and heat condction. From the experiments, we can draw the following conclusions:

(1) Due to the increase of the fuel consumption when the fuel spreads, the fuel quantity that is available to increase the pool diameter varies at different burning times. During the initial time, the discharge rate is larger than the fuel consumption by burning and excess fuel is available to spread under the gravity effect. For the long-time burning, the quasi-steady burning radius is determined by the regression rate for a certain discharge condition. Based on the spread rate variations, the spread behavior of spill fires on glass can be divided into four phases: (i) spread burning phase, (ii) shrink burning phase, (iii) quasi-steady burning phase and (iv) extinguishment phase.

(2) The regression rate of spill fires is lower than that of pool fires and the ratio is around 0.89 during the quasi-steady burning phase. During the spill burning process, the penetrated thermal radiation and the heat conduction can achieve approximately $2.5 \mathrm{~kW} / \mathrm{m}^{2}$ and $2.8 \mathrm{~kW} / \mathrm{m}^{2}$ respectively, which clearly show that the radiative penetration and the heat conduction both have an obvious effect on the regression rate decrease. These two components need to be considered in a regression rate model of spill fires.

(3) A complete spread model for spill fires was developed. In this model, the spread process, shrink burning process and quasi-steady burning process are all considered. The real-time fuel consumption due to burning is estimated based on the modification of Ditch's regression rate model.

The results of these experiments provide insight into the entire spread process for continuous spill fires and provide an analytical method to estimate the regression rate for spill fires. The developed spread model lays a solid foundation for the analysis of liquid fuel fire events. The heat conduction and penetrated thermal radiation are preliminary analyzed. Clearly, the regression rate can be expected to be different for spread on water and for spread on concrete. Therefore, we should note that it is still need many works to perform before building an accurate model in some specific applications. In future work, the different substrates will be used as the spread surface and the penetrated radiation will be further investigated. 


\section{ACKNOWLEDGEMENTS}

This study was sponsored by Ministry of Science and Technology of the People's Republic of China under Grant No. 2015BAK12B01, State Key Laboratory of Safety and Control for Chemicals, and Short-Term Visiting Fund of Tsinghua University.

\section{REFERENCES}

[1] Hussein, M., Jin, M., Weaver, J. W., (2002) Development and verification of a screening model for surface spreading of petroleum, Journal of Contaminant Hydrology 57(3-4):281-302, http://dx.doi.org/10.1016/s0169-7722(01)00220-0

[2] Basha, O., Olewski T., Véchot, L., Castier, M. and Mannan S., (2014) Modeling of pool spreading of LNG on land, Journal of Loss Prevention in the Process Industries 30, 307-314.

http://dx.doi.org/10.1016/j.jlp.2014.04.012

[3] Luketa-Hanlin, A., (2006) A review of large-scale LNG spills: Experiments and modeling. Journal of Hazardous Materials 132(2-3):119-140,

http://dx.doi.org/10.1016/j.jhazmat.2005.10.008

[4] Fay, J. A., (2003) Model of spills and fires from LNG and oil tankers, Journal of Hazardous Materials 96(2-3):171-188, http://dx.doi.org/10.1016/s0140-6701(03)82832-1

[5] Webber, D. M., Gant S. E., Ivings, M. J., and Jagger, S. F., "LNG source term models for hazard analysis: A review of the state-of-the-art and an approach to model assessment," Buxton,

Derbyshire, UK: HSE Books, Report RR789, 2000,

http://www.hse.gov.uk/research/rrpdf/rr789.pdf. (2010).

[6] Beyler, C. L., "Fire Hazard Calculations for Large, Open Hydrocarbon Fires”, The SFPE Handbook of Fire Protection Engineering ( $3^{\text {nd }} e d$ ), DiNenno, P.J., National Fire Protection Association, Quincy, 2002.

[7] Babrauskas, V., (1983) Estimating Large Pool Fire Burning Rates, Fire Technology 19, 251-261, http://dx.doi.org/10.1007/BF02380810

[8] Ditch, B. D., de Ris, J. L., Blanchat, T. K., Chaos, M., Bill, R. G., and Dorofeev, S. B., (2013)

Pool fires-An empirical correlation. Combustion and Flame 160(12), 2964-2974,

http://dx.doi.org/10.1016/j.combustflame.2013.06.020

[9] Zhao, J., Huang, H., Li, Y., Su, B., Zhang, N., (2016) Experimental and modeling study of the behavior of a large-scale spill fire on a water layer, Journal of Loss Prevention in the Process Industries 43:514-520, http://dx.doi.org/10.1016/j.jlp.2016.07.014

[10] Gottuk, D., Scheffey, J., Williams, F., Gott, J., and Tabet, R., Optical Fire Detection for Military Aircraft Hangars: Final Report on OFD Performance to Fuel Spill Fires and Optical Stresses, Naval Research Laboratory NRL/MR/6180—00-8457, Washington D.C., 2001, pp. 1-341.

[11] Mealy, C, Benfer, M, Gottuk ,D T., “A study of the parameters influencing liquid fuel burning rates,” Fire Safety Science -- Proceedings of the Eleventh International Symposium, International Association for Fire Safety Science, 2011, pp 945-958.

[12] Gottuk, D.T., and White, D.A., “Liquid Fuel Fires,” The SFPE Handbook of Fire Protection Engineering ( $5^{\text {nd }}$ ed), Morgan J. H. (ed.), Springer, 2015

[13] Guo, S., Peng, M., Ruan, J., and Wan, W., (2013) Cause analysis of the fire and explosion during crude oil desulfurization in China. Journal of Loss Prevention in the Process Industries, 26(6), 961-967, http://dx.doi.org/10.1016/j.jlp.2013.09.013

[14] Fay, J. A., The Spread of Oil slicks on a Calm Sea, Fluid Mechanics Laboratory Report, Department of Mechanical Engineering, MIT, Cambridge, Mass., 1969. 
[15] Webber, D.M., Model for Pool Spreading, Evaporation and Solution on Land and Water (PVAP) Verification Manual, in PHAST 6.0 Manual, 2000.

[16] Brambilla, S., Manca, D., (2008) Accidents involving liquids: A step ahead in modeling pool spreading, evaporation and burning, Journal of Hazardous Materials 161(2-3):1265-80, http://dx.doi.org/10.1016/j.jhazmat.2008.04.109

[17] Webber, D. M., (2012) On models of spreading pools, Journal of Loss Prevention in the Process Industries 25(6):923-926, http://dx.doi.org/10.1016/j.jlp.2012.05.003

[18] Tewarson, A., Smoke Point Height and Fire Properties of Materials, Report NISTGCR-88-555, National Institute of Standards and Technology, Gaithersburg, MD, 1988. 